\title{
Unit-Ideas Unleashed: A Reinterpretation and Reassessment of Lovejovian Methodology in the History of Ideas*
}

\author{
Carl Knight \\ University ofJohannesburg and University of Glasgow \\ carl.knight@glasgow.ac.uk
}

\begin{abstract}
This article argues for an unconventional interpretation of Arthur O. Lovejoy's distinctive approach to method in the history of ideas. It is maintained that the value of the central concept of the 'unit-idea' has been misunderstood by friends and foes alike. The commonality of unit-ideas at different times and places is often defined in terms of familial resemblance. But such an approach must necessarily define unit-ideas as being something other than the smallest conceptual unit. It is therefore in tension with Lovejoy's methodological prescription and, more importantly, disregards a potentially important aspect of intellectual history - the smaller conceptual units themselves. In response to this, an alternative interpretation of unit-ideas as 'elemental' - as the smallest identifiable conceptual components - is put forward. Unlike the familial resemblance approach, the elemental approach can provide a plausible explanation for changes in ideas. These are construed as being either the creation of new unit-ideas, the disappearance of existing ones, or alterations in the groups of unit-ideas that compose idea-complexes. The focus on the movement of unit-ideas and idea-complexes through history can also be sensitive to contextual issues, carefully distinguishing the different meanings that single words may have, in much the way that both Lovejoy and his influential critic Quentin Skinner suggest.
\end{abstract}

\section{Keywords}

Arthur O. Lovejoy, causality, change, context, Quentin Skinner

\footnotetext{
*) I would like to thank Jon Parkin and anonymous referees for their helpful comments on earlier versions of this article.
} 


\section{Introduction}

Arthur O. Lovejoy's The Great Chain of Being has left a deep impression on intellectual history since its publication in $1936 .^{1}$ This impression is twofold, affecting both the method and practice of intellectual history. But the impact of Lovejoy's approach to the former, as set out in the first chapter of his great work and expanded on in subsequent essays, has undoubtedly been on the wane for many decades. Kenneth Minogue has remarked that '[ $t$ ] he actual context of such ideas [as The Great Chain of Being] was, for Lovejoy, a tiny hook suitable for chronological docketing and identification. Since that time, theory (though not invariably practice) has gone entirely in the opposite direction'. ${ }^{2}$ Francis Oakley writes that, for all its former acclaim, The Great Chain of Being is now, one cannot help feeling, more often dismissed than it is read'. ${ }^{3}$

In my view, this state of affairs has arisen largely because existing examinations of Lovejoy's writings on method do not do them justice. This article offers a reinterpretation and reassessment of the Lovejovian methodology. In so doing it presents a case for the restoration of that methodology to its position in the front rank of approaches to intellectual history.

My primary focus is Lovejoy's concept of the 'unit-idea', the conceptual element which he says should be used in the analysis of the history of ideas. The first part of the article suggests that the common 'familial resemblance' construal of unit-ideas appears to be at odds with key parts of Lovejoy's description, and leaves important questions unanswered. I favor a more basic 'elemental' construal. The middle section of the article asks whether this Lovejovian methodology can plausibly explain historical change and causality. I maintain that while the view can not account for internal

1) Arthur O. Lovejoy, The Great Chain of Being: A Study of the History of an Idea (Cambridge, MA: Harvard University Press, 1936).

2) Kenneth Minogue, 'Method in Intellectual History: Quentin Skinner's Foundations', in Meaning and Context: Quentin Skinner and his Critics, ed. James Tully (Princeton: Princeton University Press, 1988), 186. For the rise in popularity of contextualism see Robert Darnton, 'Intellectual and Cultural History', in The Past Before Us: Contemporary Historical Writing in the United States, ed. Michael Kammen (Ithaca, NY: Cornell University Press, 1980). For my own comments on the (supposed) conflict between contextualism and Lovejovianism see section IV below.

3) Francis Oakley, Natural Law, Laws of Nature, Natural Rights: Continuity and Discontinuity in the History of Ideas (New York: Continuum, 2005), p. 14. 
changes in unit-ideas, this is a strength of the view, saving it from the paradox such cases present for familial resemblance. It can also, in large part, plausibly account for the causality of changes in idea-complexes by means of its doctrine of change. The emergence of unit-ideas themselves is somewhat harder to explain, but this is no failing of the approach. Towards the end of the article I assess the charge that the Lovejovian approach treats ideas in a context-blind manner. I find that the charge unreasonably equates ideas and words, and relies on a misunderstanding of the approach. Not only was Lovejoy acutely sensitive to contextual issues, but one of his most prominent critics, Quentin Skinner, in fact deploys Lovejovian methods in his contextualist histories of political thought.

\section{Unit-ideas: familial or elemental?}

Lovejoy takes the unit-idea, the basic conceptual element, as the main point of focus for the historian of ideas. But what exactly is a unit-idea? One way of going about answering this question is to look at the three unit-ideas the principles of plenitude, continuity, and gradation - that Lovejoy actually identifies in The Great Chain of Being. He claims that each of these principles is found in many provinces of intellectual history. For example, the principle of plenitude - which states, in essence, that everything that can be, will be - can be traced from Plato and the Neo-Platonists, through Augustine and the Christian theologians of the Middle Ages, to Bruno, Leibniz and Kant. However, the continuity of this unit-idea is controversial.

Jaakko Hintikka challenged how Lovejoy used the concept of the unitidea in both theory and practice. ${ }^{4}$ His argument proceeded by focusing on the principle of plenitude, for he believed that if Lovejoy's prime example of a unit-idea was not actually a unit-idea, the very possibility of unit-ideas must be thrown into doubt. Hintikka objected, firstly, that the principle is not a conceptual element but rather a compound of elements; and secondly, that it has different consequences in different contexts. On the face of it, both these points appear to be correct. The principle is not especially basic or fundamental; several concepts evidently have to be used in arriving

\footnotetext{
4) Jaakko Hintikka, 'Gaps in the Great Chain of Being: An Examination in the Methodology of the History of Ideas', Proceedings and Addresses of the American Philosophical Association 49 (1976): 22-38.
} 
at it, or even in expressing it. Equally, the principle obviously did not mean exactly the same thing in, say, classical Athens and eighteenth-century Germany. However, Moltke Gram and Richard Martin have argued that the principle of plenitude 'should perhaps be looked on as a class of laws all having a suitable structural resemblance'. ${ }^{5}$ If this were allowed, neither of Hintikka's objections hit home, for it is simply granted that the principle is not, after all, particularly basic, and that it varies in its effects from context to context. As Daniel Wilson, another adherent of the familial resemblance approach, attests, it does not seem inconsistent with Lovejoy's practice in The Great Chain of Being, although the phrase unit-idea is on those grounds ill-chosen. ${ }^{6}$ But how consistent is it with what Lovejoy says about methodology in the history of ideas?

Lovejoy describes the 'initial procedure' of the history of ideas as 'somewhat analogous to that of analytical chemistry. In dealing with the history of philosophical doctrines, for example, it cuts into the hard and fast individual systems and, for its own purposes, breaks them into their component elements, into what may be called their unit-ideas'. ${ }^{7}$ This suggests that a unit-idea is equivalent to, say, Hydrogen; a doctrine would be equivalent to hydrochloric acid (which contains both Hydrogen and Chloride). Now let me contrast this with Gram and Martin's conception of a unit-idea as a group of ideas with a familial resemblance. In the terms of my analogy, this claim might be made in two ways. First, the proposition that a unit-idea is equivalent to a group of compounds, such as acids, which share common characteristics (for example, dissociating on contact with water to release hydrogen ions). Second, the claim that a unit-idea is equivalent to a group of elements, such as alkali metals, which share common characteristics (for example, having low melting points and densities and reacting violently with water). I do not think the first claim squares very well with Lovejoy's methodology, at least if we take him at his word that he views unit-ideas as analogous to elements, not compounds. The second claim, which simply

5) Moltke S. Gram and Richard S. Martin, 'The Perils of Plenitude: Hintikka contra Lovejoy', Journal of the History of Ideas 41 (1980): 497-511, at 511.

6) Daniel J. Wilson, 'Lovejoy's The Great Chain of Being after Fifty Years' in The History of Ideas: Canon and Variations, ed. D.R. Kelley (Rochester, NY: University of Rochester Press, 1990), 175-6. Wilson's analysis is accepted in Wouter J. Hanegraff, 'Emprical Method in the Study of Esotericism', Method and Theory in the Study of Religion 7 (1995), 99-129.

7) Lovejoy, The Great Chain of Being, 3 . 
shifts the metaphor so that elements become atoms and compounds become elements, is a little more credible. Perhaps Lovejoy would be prepared to shift his metaphor in a parallel way. This does, however, seem a little strained. The glaringly obvious question arises: what of the smaller units? Where compounds become elements, this still leaves atoms unaccounted for. But if those working in terms of (what they call) unit-ideas overlook these atoms, who exactly will notice them? If our interest is the breaking down of ideas into their component parts, as Lovejoy suggests, why stop just here?

The central point is that where two ideas share familial resemblance, there may be some characteristic which one holds and the other does not. After all, to share familial resemblance is not necessarily to be qualitatively identical. ${ }^{8}$ But such a characteristic must relate to some identifiable component. Thus, any talk of familial resemblance is already (at least) one level up from the smallest identifiable components. This is not in itself to say that the study of families of compounds, or unit-idea clusters, is inherently flawed. But it is to say that Gram and Martin leave an unexplored option, an option which I think is both attractive and more in keeping with the spirit of what Lovejoy says when he is in methodological mode. This is to study the smallest parts themselves. We might call these elemental unitideas, the contrast being with Gram and Martin's familial unit-ideas. Hereafter 'unit-idea' refers to an elemental unit-idea, while an 'idea-complex' or 'compound' is an idea composed of more than one elemental unit-idea. A familial unit-idea would therefore be a group of compounds sharing certain common (elemental) unit-ideas.

It might be objected that all this is very well, but if I cannot identify 'smaller' ideas than the principles (such as that of plenitude) then I am wasting my breath. But candidates are all around us. Possible examples of elemental unit-ideas would be the ideas denoted by the words 'God', 'Man', and 'Equality'. In all these cases it must be emphasized that it is the smallest identifiable idea which is of interest: we would strip out all religious, normative and social connotations, right down to, say, the mere concept of parity (in any context or regard whatsoever).

\footnotetext{
8) To be qualitatively identical is to be exactly alike. The familial resemblance view posits that two ideas may be numerically identical, that is, one and the same idea, without being qualitatively identical. For the distinction between qualitative and numerical identity see Derek Parfit, Reasons and Persons (Oxford: Oxford University Press, 1984), pp. 201-2.
} 
The further complaint might then be made that, in attending to such simple concepts, the interest of intellectual history is lost. Nils Bjorn Kvastad rejects such an approach in favor of a familial one on the grounds that it ignores concepts 'of broad cultural or philosophical relevance'. ${ }^{9}$ But what I have described so far is only the beginning. The trick comes once several unit-ideas have been identified and are brought together, to create the very compounds Gram and Martin's, Wilson's, and Kvastad's approaches claim to be identifying. ${ }^{10}$ Such a combination might be that 'all men are equal', where each word is taken to stand for a unit-idea. (For presentational convenience I will hereafter refer to the words used to indicate unit-ideas - for example, 'all', 'men', and 'equal' - and idea-complexes - for example, "God makes all men equal" - as though they were the ideas themselves. Where I mean to refer to the word itself I indicate this. That there is a distinction here is particularly important to section IV below.) We can even draw familial resemblances a la Gram and Martin and others. Thus we might class as in the egalitarian family both the previous compound and the ideacomplex 'God makes all men equal'. Both compounds contain the unitideas 'all', 'men', and 'equal', but the latter adds the unit-ideas 'God' and 'makes' and removes the unit-idea 'are'. Naturally, this approach can be extended to cover any interesting compound.

The chief advantage of the elemental approach is that it brings those variations that do hold between different culturally or philosophically significant idea-complexes into sharp relief. A historian who is methodologically predisposed to break ideas down into their smallest constituent parts is far less likely to overlook conceptually significant variations between different persons' and - particularly - different cultures' ideas than a historian who is ever on the lookout for ideas with certain shared characteristics.

Kvastad considers something very similar to the elemental unit-ideas approach, but notes the danger of 'endless regress':

There is ... no reason to regard the alleged unit-ideas expressed by ' $\mathrm{D}$ ' as irreductible units. Each of them is reductible in the sense that the words expressing them in their turn can be defined by other words. We can then substitute each word in ' $\mathrm{D}$ ' with its definition, and get a new definiens expression

\footnotetext{
9) Nils Bjorn Kvastad, 'On Method in the History of Ideas', International Logic Review 17-8 (1978): 96-110, at 101. 10) See Lovejoy, The Great Chain of Being, 3-4.
} 
'D1' .... But each word in 'D1' has also its definition .... In this way we can go on and get an endless series of definiens expressions ' $\mathrm{D} 1$, ' $\mathrm{D} 2$ ', ..., (Dn), ... But when this is possible I don't think it is very meaningful to say that the unit ideas expressed by 'D' are irreductible, when they can be analyzed by such an endless series of expressions. ${ }^{11}$

However, this danger can be forestalled by bringing the main advantage of identifying unit-ideas to the fore - that it shows differences between ideacomplexes in different stages of history that might otherwise have slid from view. Unit ideas are 'those simpler parts of the meaning of ideas which make it easier for the mind to grasp their total meaning'. ${ }^{12}$ It is true that the word 'equality', say, can be given several definitions, but so long as we do not find variations in the meaning of 'equality' which are independent of the other unit-ideas with which it forms a complex, its status as denoting a unit-idea is secure.

A similar response is considered by Kvastad, who draws an analogy with the 'primitives' used together with grammatical rules to make up languages: 'we may by arbitrary convention declare some words to be basic and indefinable'. ${ }^{13}$ Certainly elemental unit-ideas are similar to primitives in that we define them as unit-ideas for functional purposes. But there is an important difference in that we are usually to consider particular unit-ideas as potentially subject to reclassification as idea-complexes. ${ }^{14}$ This occurs if it is found that the putative unit-ideas are themselves composed of smaller elements. Evidently this does not undermine the method, but rather calls for further historical research within the same methodological paradigm. Our research might show that 'God' is in fact a compound made up of elements such as 'good', 'omnipresent', 'omnipotent', 'omniscient', and the like. This would be brought out where we found variations in the use of the concept of 'God', such that it became apparent that it was a family of compounds made up of some common, but some different, elements. And of course these elements may themselves be compounds. 'Omniscient', for example, contains the elements 'all' and 'knowing'. Likewise, we may find

\footnotetext{
11) Kvastad, 99 .

12) Philip P. Wiener, 'Some Remarks on Professor Mink's Views of Methodology in the History of Ideas', Eighteenth Century Studies 2 (1969): 311-7, at 313.

13) Kvastad, 99, emphasis suppressed.

14) I do not mean to deny that it is impossible to reach the bedrock of true unit-ideas, just that it is very hard to know that it has been reached.
} 
that 'makes' includes, among other unit-ideas, 'are', at least in past tense form, since 'makes' involves the notion that things have changed from how they were.

What I am suggesting in practice, then, is a regressive program of study. We start at the top with idea-complexes that may initially seem to be fundamental. Ultimately we work our way down to foundational elements as each layer of (what were taken to be) 'unit-ideas' are revealed in fact to be compounds due to the variations the researcher identifies within them. The thorough investigation of unit-ideas is a matter of identifying the prima facie identical ideas that occur at different times and places, and then discerning relatively small but vital semantic variations.

On this account, the history of ideas becomes a massively time consuming affair, ultimately requiring far greater attention to detail than Lovejoy's relatively broad sweep of intellectual history. The divergence between Lovejoy's theory and practice might be seen as a consequence of him only scraping the surface, engaging with large compounds only, whilst suggesting he had got to the bottom, or near to it. ${ }^{15}$ This is of course forgivable; no single person can hope to completely unravel such complex intellectual history, and Lovejoy did as much as anyone could hope to.

While Gram and Martin, Wilson, and Kvastad are happy to describe this scraping of the surface as the finished article, I view that kind of research as the start of a deeper incision into intellectual history. This appears to be consistent with both Lovejoy's methodological prescriptions ${ }^{16}$ and the fact that, outside the methodological introductory chapter, Lovejoy does not use the term 'unit-idea' anywhere in The Great Chain of Being. Leo Catana cites this fact in support of his view that Lovejoy's stated methodological position was 'more of a rhetorical declaration - intended to produce the conviction in the minds of his readers that history of ideas was distinct from history of philosophy and thus deserved institutional independence - than an adequate description of the method actually practiced'. ${ }^{17}$ This account

15) Thomas Bredsdorff, 'Lovejovianism - Or the Ideological Mechanism', Orbis Litterarum 30 (1975): 1-27, at 10-12; 'Lovejoy's Idea of "Idea"', New Literary History 8 (1977): 195-211, at 199-200.

16) Note that Kvastad views his family resemblance approach as an alternative to Lovejoy's; see Kvastad, 101-4.

17) Leo Catana, 'Lovejoy's Readings of Bruno: Or How Nineteenth-century History of Philosophy was "Transformed" into the History of Ideas', Journal of the History of Ideas 71 (2010): 91-112, at 93. 
of Lovejoy's motivation might go some way to explaining why Lovejoy claimed in his studies to be examining unit-ideas. If he had instead claimed to be examining idea-complexes, he would have placed history of ideas uncomfortably close to nineteenth-century history of philosophy, whose key concepts of 'principle' and 'system of philosophy' are forms of ideacomplex. The interdisciplinary character of his approach would still distinguish it, but perhaps not enough for his purposes.

It is, of course, understandable to want to reconcile Lovejoy's theory and practice, given his significance in both fields of the history of ideas. But I think we can salvage both the history and theory by being more honest about the relation between the two in Lovejoy. Indeed, it is arguable that his histories of ideas were, even by his own lights, second best approximations, insisting as he did that interdisciplinary collaboration on a scale previously unimagined by humanists was required to provide full accounts of unit-ideas. ${ }^{18}$ Lovejoy could almost have been providing a rationale for his own work when he writes that " $[\mathrm{e}] \mathrm{ven}$ the partial realization of such a program would do much, I cannot but think, to give a needed unifying background to many now unconnected, and consequently, poorly understood facts'. ${ }^{19}$ His historical work was remarkable, but that should not distract us from the fact that Lovejoy's methodology suggests an appealing ideal that might be even better approximated with greater resources, where those resources are targeted as that methodology suggests.

\section{Change and causality}

It may seem that my account of unit-ideas as elemental has the consequence that individual unit-ideas themselves cannot undergo change. Is this correct? And insofar as this is correct, does it have detrimental effects for a Lovejovian account of historical change which uses unit-ideas?

First of all, I should indicate what I mean by change in an idea. For there to be change in an idea, there must be an idea at $\mathrm{T}_{2}$ that is either (a) absent at $\mathrm{T}_{1}$ and/or $\mathrm{T}_{3}$, or $(\mathrm{b})$ present at $\mathrm{T}_{1}$ and/or $\mathrm{T}_{3}$ but non-qualitatively identical.

18) Arthur O. Lovejoy, 'The Historiography of Ideas' in Essays in the History of Ideas (Baltimore: John Hopkins University Press, 1948); see Anthony Grafton, 'The History of Ideas: Precept and Practice, 1950-200o and Beyond', Journal of the History of Ideas 67 (2006): 1-32, at 7-8.

19) Lovejoy, The Great Chain of Being, 16. 
On this definition, it is obvious that type-(a) or existential changes in unitideas can occur on the elemental account, in two ways. Elemental unitideas can come into existence, or cease to exist.

Maurice Mandelbaum asserts against Lovejoy that some ideas are recurrent, not continuous, and may occur quite independently of whether they have previously been held, just as archaeologists sometimes find a people invented a certain technology. ${ }^{20}$ More recently Mark Bevir has warned 'that we should eschew essentialism: we should be wary of any talk of "primary and persistent" objects in the history of ideas'. ${ }^{21}$ But is Lovejoy, and are Lovejovians, committed to such talk? To be sure, the main thrust of Lovejoy's approach is the tracing of unit-ideas through history. But he is quite clear that 'absolute novelty' sometimes arises. ${ }^{22}$ The main thrust of his studies is simply to show those interesting cases in which, contrary to first appearances, this is not the case. On my favored version of the Lovejovian methodology change can occur in the set of unit-ideas, for new unitideas can appear. Once they have appeared they do not undergo internal change. But even then, they can still disappear in the sense of nobody subscribing to them. Unit-ideas are contingently existent and persistent.

Any worry about the elemental account's inability to account for change must, then, be expressed in terms of its inability to account for type-(b) or internal change. That is, it might be thought a shortfall of the view that it says that unit-ideas begin and end, but cannot change their content along the way. Is this so?

There may seem to be an easy way out for the elemental approach. As I noted above, putative unit-ideas may prove, on closer inspection, to be idea-complexes. In that case, it may seem that elemental unit-ideas can change internally after all, as the assessments of historians of ideas vary over time. Later historians may recognize additional content in ideas. But this strikes me as a strange way of generating internal change. After all, if a putative unit-idea later proves to be an idea-complex, the explanation is simply that somebody made a mistake. What we are fundamentally interested in is surely the fact, not the struggle to uncover it. If an idea was once

20) Maurice Mandelbaum, 'On Lovejoy's Historiography', in The History of Ideas: An Introduction to Method, ed. Preston King (London: Croom Helm, 1983), 202.

21) Mark Bevir, The Logic of the History of Ideas (Cambridge: Cambridge University Press, 1999), 202.

22) Lovejoy, The Great Chain of Being, 4. 
thought to be a unit-idea and was later considered an idea-complex, none of that matters except insofar as it may help our understanding of the actual historical phenomenon. And if that phenomenon was ever an elemental unit-idea, it cannot have ever been an idea-complex. In short, false beliefs about unit-ideas can not create changes in them.

It may seem a clear advantage of the family resemblance approach that it can account for the internal changes in unit-ideas that the elemental approach can not. But such changes, at least as described by the family resemblance approach, are highly problematic. It might seem reasonable to say that concepts at $T_{1}$ and $T_{2}$ are one unit-idea as they have some significant commonality of content, and that concepts at $\mathrm{T}_{2}$ and $\mathrm{T}_{3}$ are one unit-idea as they have some significant commonality of content. But that is quite consistent with the $T_{1}$ and $T_{3}$ concepts having no common content, as their respective similarities with the $\mathrm{T}_{2}$ concept may be on account of different parts of that concept. This presents the familial resemblance theorist with a dilemma. The concepts at $\mathrm{T}_{1}$ and $\mathrm{T}_{3}$ might be treated as the same unit-idea, and the process as one of type-(b) (internal) change. But that is counterintuitive given that $\mathrm{T}_{1}$ and $\mathrm{T}_{3}$ have no conceptual similarity. ${ }^{23}$ Alternatively, the concepts at $\mathrm{T}_{1}$ and $\mathrm{T}_{3}$ might not be treated as the same unitidea, and the process instead described as type-(a) change - as some ideas beginning and others starting. But that amounts to abandoning familial resemblance. As Jouni-Matti Kuukkanen puts it, ' $t$ t] he family-resemblance model... pointedly says that no set of features has to be shared by all, but merely the successive overlapping of features is enough for conceptual

\footnotetext{
23) They are obviously qualitatively different, and they also seem to be clearly numerically different (for the distinction see above, note 8). A person might undergo a process of change of beliefs and other psychology, while remaining numerically identical with their prior self, as continuity of psychology might be enough to support identity (see Parfit, part III). For instance, a 20 year old would often be thought of as the same person as her future 60 year old self, even though they had little psychology in common, provided that this divergence will come about in a continuous way - for instance, the twenty year old's beliefs today are almost the same as her beliefs tomorrow, which are almost the same as her beliefs the next day, and so on. But continuity is clearly not enough for identity of ideas. If we start off with the idea that God is good, and through a series of small changes arrive at the view that God is bad, it clearly does not follow that, in this case, God is good is numerically identical to God is bad. Someone who, when they were twenty, thought that God was (without qualification) good, and when they were sixty thought that God was (without qualification) bad, is not endorsing one and the same idea at these two points.
} 
membership'. ${ }^{24}$ So while the promise of accounting for internal changes in unit-ideas initially looks like an advantage for the family resemblance approach, it proves to be a can of worms. Not only is it not an advantage, it presents a powerful counterexample to the view.

Note that this case presents no difficulty for the elemental view. It simply states, without contradiction, that $\mathrm{T}_{1}$ and $\mathrm{T}_{3}$ are not the same unit-idea, and that type-(a) change is at hand. I therefore stand by the notion that type-(b) changes in elemental unit-ideas are not possible. Far from exposing a weakness of the elemental view, this demonstrates its strength of treating wholly dissimilar ideas as non-numerically identical.

So much, then, for change in unit-ideas. What about causality? Lovejoy's theory of the forces which drive change in the history of ideas is centered on the internal conflicts historical figures experience between their different beliefs, between their different feelings, and between their beliefs and feelings. ${ }^{25}$ An example of the last type of conflict would be that between Schlegel's early Kantian aestheticism and his feeling that poetry should retain the personal touch of the poet. ${ }^{26}$ As a result of this conflict Schlegel adopted his romanticism. Of course, this inner conflict could have been resolved in other ways, or not resolved at all, but Lovejoy seems to have identified a force which explains the conditions which gave rise to the move to romanticism which Schlegel happened to make. In this way, 'Lovejoy's doctrine of forces ... is a dialectic without laws, which is to say a dialectic in which outcomes are historically intelligible although not theoretically deducible'. ${ }^{27}$

There is a preliminary problem with Lovejoy's account of such conflicts. Philip Wiener maintains that 'Lovejoy has committed the circular fallacy of explaining the differences of philosophers by reference to their innate "temperaments" or "congenital diversity" which we can characterize and classify after we examine the philosophical assumptions adopted unquestioningly by each of the philosophers we have "typed" '.28 Wiener implies

\footnotetext{
24) Jouni-Matti Kuukkanen, 'Making Sense of Conceptual Change', History and Theory 47

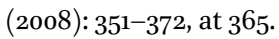

25) Mink, 210-2.

26) Arthur O. Lovejoy, 'The Meaning of "Romantic” in Early German Romanticism', in Essays in the History of Ideas.

27) Mink, 212.

28) Philip P. Wiener, 'The Central Role of Time in Lovejoy's Philosophy', Philosophy and Phenomenological Research 23 (1963): 480-92, at 491.
} 
that Lovejoy allows insufficient scope for critical intervention on the part of the subject, viewing the generation of beliefs - such as Schlegel's romanticism - as a mere consequence of particular natures - such as Schlegel's feeling about poetry. Wiener suggests, reasonably enough, that Lovejoy's concept of human nature needs to be variable in the light of reflection. Likewise, feelings should be understood as in part the result of critical thought. This seems quite consistent with the Lovejovian approach to the history of ideas that I have described. For instance, it is quite possible for someone to arrive at some belief or feeling after exploring the interconnections of various unit-ideas and idea-complexes. Given the numbers of unitideas, and the range of combinations of them that are available, it is obvious that no person could consider them all. Those which are considered will, to some extent, be set by the intellectual environment, personal character, and so on, but there will also be an element of randomness - a chance meeting or book discovery may sometimes provide the impetus for a line of thought that would not otherwise have been pursued.

Louis Mink suggests the apparently deeper problem that unit-ideas are in conflict with Lovejoy's notion of historical change. ${ }^{29}$ Mink emphasizes the contrast between the two 'conceptual systems' presupposed:

the conceptual system in terms of which his [Lovejoy's] notion of 'unit-ideas' is intelligible - roughly the conceptual system associated with our experience and understanding of physical things - does not comport amicably with the conceptual system in terms of which his explanation of 'forces' are intelligible - roughly the conceptual system associated with our experience and understanding of human thought and feeling. ${ }^{30}$

This complaint is, if anything, more applicable to elemental unit-ideas than familial unit-ideas. It is, however, somewhat opaque. Nevertheless, I think that some tentative comments about these conceptual systems may hint that the significance Mink apparently attaches to his contrast is overdrawn. I am not sure that we should grant that the Lovejovian account of unit-ideas and forces is committed to relevantly different conceptual systems. But even allowing that it is, these conceptual systems are not

29) Louis Mink, 'Change and Causality in the History of Ideas' in his Historical Understanding, ed. B. Fay, E.O. Golob and R.T. Vann (Ithaca, NY: Cornell University Press, 1987). 30) Mink, 206. 
discontinuous with one another. They are just at opposite ends of a continuum of conscious thought that, very approximately, runs from our own thoughts and feelings, through those of persons we know, through that of other people, through non-human animals, through other living things, and finally into physical objects. It is certainly a big conceptual jump from a human stranger's thoughts and feelings to a physical object, but it is maybe no bigger than that from our own thoughts and feelings to that of strangers. In fact there are important similarities between the way we understand the interactions of physical objects and the way we understand the decision-making processes of people we do not know. In both cases we attempt to isolate inputs (for example, momentum on the one hand, childhood experiences on the other) that may affect the outcome but we also accept that the outcome may be other than that one would expect from the identified inputs. We explain this as a consequence of our failure to identify all the inputs - we may have failed to account for magnetic forces or for effects of upbringing.

In any case, I see no difficulty in imagining conflicts in beliefs and feelings where these beliefs and feelings are unit-ideas, or, as is more likely, combinations of unit-ideas. Mink implies that such a scheme cannot render ideas genuinely intelligible, for 'it is impossible to understand the "interplay" or "interaction" of ideas if in fact neither is changed by this process'. ${ }^{31}$ But this problem is avoided if we focus on elemental unit-ideas. If it is said that internal change of unit-ideas themselves must be accounted for, then a different conception of unit-ideas is simply being asserted against elemental unit-ideas without any argument for why that view is preferable. If, however, it is being said that internal change in idea-complexes must be accounted for, there is no divergence from the Lovejovian position I have described, which accounts for such changes as a change in the combination of unit-ideas. Unit-ideas such as the ones I have provisionally identified are so small that they will never come into any conflict with one another in any meaningful way.

I say 'meaningful' conflict for there could be many unmeaningful conflicts, that is ones which no one would claim could give rise to a change in ideas regardless of the conceptual scheme they were using. For example, 'good' and 'bad' might be unit-ideas which come into an unmeaningful

31) Mink, 210. 
conflict. This is only a conflict in the sense that 'yes' and 'no' are in conflict that is, in serving directly opposed roles. Conflict using these unit-ideas only acquires meaning when they are used in combination with other unitideas, where they contradictorily predicate the same object. Hence 'God is good' versus 'God is bad' is a meaningful conflict between idea-complexes which might give rise to many new idea-complexes, depending of course on the beliefs and feelings of the individual in question.

This points us towards dissipating Mink's bifurcation of Lovejoy's thought, viz: 'Lovejoy's doctrine of forces explains why there is a history of ideas; but his doctrine of elements characterizes ideas in such a way that (like physical constants or the number 2) they cannot have a history at all, that is, undergo development and change'. ${ }^{32}$ We say simply that there is a history of change in ideas, but that internal change or 'development' occurs only in one class of ideas, idea-complexes, not in the class of unit-ideas, whose members cannot change by virtue of belonging to that class. ${ }^{33}$ As Kathleen Duffin elaborates, Lovejoy's philosophy of history is 'emergent evolutionary', allowing that conceptual mutations may take place and may well enrich existing reality. ${ }^{34}$ I understand these mutations as being the rearrangement of unit-ideas within idea-complexes.

Mink's objection may seem to have a further dimension, one which concerns the ontological status of unit-ideas. Others have objected more explicitly on this score. Deborah J. Coon describes Lovejoy's ideas as 'ahistorical', as 'neo-Platonic universals', seeing them in conflict with the view that '[c]onceptual systems are like evolving species'. ${ }^{35}$ And Bevir similarly asks 'how a Platonic form can exist for some time and then whither'. ${ }^{36}$ But insofar as my Lovejovian approach is metaphysically committed, it is not to Platonic forms, nor in a way that conflicts with conceptual evolution. The approach does seem to be committed to a form of ideas that can recur. For instance, unit-ideas can not be construed as ideas in the special sense Frege gives to the term: '[i]t is so much of the essence of any one of my ideas to be

\footnotetext{
32) Mink, 206, original emphasis.

33) Wiener, 'Some Remarks on Professor Mink's Views'.

34) Kathleen E. Duffin, 'Arthur O. Lovejoy and the Emergence of Novelty', Journal of the History of Ideas 41 (1980): 267-81.

35) Deborah J. Coon, 'Of Gold and Pyrite', Biology and Philosophy 5 (1990): 493-501, at p. 497 .

36) Bevir, 61.
} 
a content of my consciousness, that any idea someone else has is, just as such, different from mine' ${ }^{37}$ To do so would make a nonsense of ideas being present in different times and places. But the relevant kind of unitidea need not, and indeed cannot, be universal, present in all times and places. This much is clear from the fact that, on my account, unit-ideas can come into and out of existence. A promising approach is to understand unit-ideas as the expressions of senses. For Frege, the sense (Sinn) of a term is what is understood by it, which allows participants to recognize the topic and engage in discussion. Frege takes the sense of a term to be objective and mind-independent. ${ }^{38}$ This makes sense itself inappropriate as a construal of unit-ideas, which I take to be subjective and mind-dependent, as they surely must be if they are to be of historical interest. An idea can indeed have no history if it does not live through those who use it. This suggests that it is not sense itself, but expressions of sense - actual written or oral statements which convey meaning - that constitute unit-ideas. Thus if 'Equality' is a unit-idea, the unit-idea is not Equality itself, which Frege would call the reference (Bedeutung), nor is it the sense or bare idea of Equality. It is rather the human expression of that idea. As I say, this approach strikes me as promising, but others may serve elemental unitideas just as well.

By harnessing Lovejoy's doctrine of change to the elemental unit-ideas and idea-complex structure we can offer an explanation of the changes in the latter idea group, in Mink's sense of being 'historically intelligible although not theoretically deducible'. Mink asserts that it is misleading to talk of this theory as uncovering causal relations, since it merely reveals influences on the historical agent's consciousness, which is the real site and cause of changes in ideas. ${ }^{39}$ However, Wiener argues that our (inevitable) failure to uncover all the causes of emergent ideas does not show that those ideas are not in some part caused by those causes we do identify. ${ }^{40}$ This is surely correct. To say that something is a cause is not to say that it is the cause; it is not to say that it is sufficient nor even necessary for the outcome,

37) Gottlob Frege, 'Thought', in The Frege Reader, ed. Michael Beaney (Oxford: Blackwell, 1997), 335 .

38) Here and elsewhere in this paragraph I draw on Richard L. Mendelsohn, The Philosophy of Gottlob Frege (Cambridge: Cambridge University Press, 2005).

39) Mink, 220-2.

40) Wiener, 'Some Remarks on Professor Mink's Views', 316. 
for something else could have played a similar role. Thus Lovejovian researchers can reveal causal relations in changes in idea-complexes whilst acknowledging that their understanding of those relations is limited to the extent that some causes, such as agents' consciousnesses, are impervious to investigation.

To be sure, we cannot hope to offer a similar account of unit-ideas, either those well established or those 'novelties'. But this is no sign of theoretical poverty. Examining the origin of elemental unit-ideas - ideas which are not formed from other ideas - would necessarily involve stepping beyond the realm of ideas and into the realm of consciousness, and even into the subconscious. This is not only an impossible task for the Lovejovian historian of ideas, but an impossible task for any historian.

Mink notes that 'nothing' about Lovejoy's doctrine and the stories of change it explains 'depends on or requires the postulation of unit-ideas identical over time and over differences of thought and culture' ${ }^{41}$ Certainly nothing I have said up to now suggests otherwise. But even if we take Mink's point, it is obviously too weak a ground for Mink's strong conclusion that the doctrine 'does not comport amicably' with unit-ideas. Changeable ideas may be consistent with the doctrine, but this by itself says nothing about whether unchangeable ones are as well. Moreover, there seem to be clear reasons for favoring an approach to the history of ideas which can coherently account for recurrence. If, as I have suggested, elemental unit-ideas may be identified and followed throughout different periods, we have the prospect of offering precise descriptions of ideas in each context, and of being able to offer an explanation of how and why they differ from related ideas in other contexts - a prospect that eludes rivals, such as familial resemblance.

\section{Context}

Perhaps the most frequently raised kind of doubt about Lovejovian methodology regards the allegedly context-blind method of investigation. Leo Spitzer, a colleague of Lovejoy's at John Hopkins, contended that he made 'the assumption of the possibility of an "unemotional idea": an idea detachable from the soul of the man who begot or received the idea, from the

41) Mink, 212. 
spiritual climate which nourished it'. ${ }^{42}$ Similarly, Mandelbaum objected that, in busying himself with the tracking of the continuities of elements, Lovejoy neglected the 'formative influences that helped determine the pattern into which they fell'. ${ }^{43}$ The discussion of the previous section, which links unit-ideas to Lovejoy's doctrine of change, should dispel the doubt in these forms, at least where unit-ideas are construed as elemental. Changes in ideas are shown to emerge from historical actors' consciousnesses in part as a response to particular conceptual milieus. Thus the Lovejovian approach, at least as I have described it, makes no assumption that ideas are 'unemotional' in Spitzer's sense, nor does it neglect Mandelbaum's 'formative influences'.

The doubt is put in stronger form by the Cambridge contextualist Quentin Skinner. He alleges that Lovejoy's 'methodology remains incapable in principle of considering or even recognizing some of the most crucial problems which must arise in any attempt to understand the relations between what a given writer may have said, and what he may be said to have meant by what he said'. ${ }^{44}$ Part of the claim is that Lovejoy does not deal with the actual use of an idea in its linguistic context and is therefore liable to lose its historical meaning. But Skinner expands on this point by noting that even if we are sensitive to differences in word usage between contexts the same word may be used differently in the same context. For example, in the Renaissance, nobilitas could denote either a 'particularly prized moral quality' or 'membership of a particular class. It might not in practice be clear which meaning we are to understand in a given case'. ${ }^{45}$ To overcome these problems, 'we must study all the various situations, which may change in complex ways, in which the given form of words can logically be used - all the functions the words can serve, all the various things that can be done with them'. ${ }^{46}$ Skinner asserts that Lovejoy fails to do this and is therefore subject to two 'essential criticisms of studying histories of "ideas"':

\footnotetext{
42) Leo Spitzer, 'Geistesgeschichte vs. History of Ideas as Applied to Hitlerism', in The History of Ideas, ed. Kelley, 35; see also Nel Grillaert, What the God-Seekers Found In Nietzsche: The Reception of Nietzsche's Übermensche by the Philosophers of the Russian Religious Renaissance (Amsterdam: Rodopi, 2008), pp. 10-11.

43) Mandelbaum, 200.

44) Quentin Skinner, 'Meaning and Understanding in the History of Ideas', History and Theory 8 (1969): $3-53$, at 31 .

45) Skinner, 'Meaning and Understanding in the History of Ideas', 36.

46) Skinner, 'Meaning and Understanding in the History of Ideas', 37.
} 
First, ... if we wish to understand a given idea, even within a given culture and at a given time, we cannot simply concentrate, a la Lovejoy, on studying the forms of words involved.... [Second,] [i]f there is good reason to insist that we can only study an idea by seeing the nature of all the occasions and activities - the language games - within which it might appear, then there must be correspondingly good reason to insist that the project of studying histories of 'ideas,' tout court, must rest on a fundamental philosophical mistake. ${ }^{47}$

Skinner is only able to reach his two criticisms through conflation of 'idea' with 'word' or 'phrase'. ${ }^{48}$ This conflation is manifest in the passage on nobilitas, where he promises to consider 'the attempt to write the history of the idea of nobilitas in the Renaissance' but proceeds to show the two different 'meaning[s] of the term' ${ }^{49}$ We can well agree that the history of a mere word (a certain combination of letters) should not be called the history of an idea, but it is quite a jump from there to the conclusion that histories of ideas are themselves intrinsically flawed.

This might nevertheless make for good criticism of Lovejoy if his theory or practice made a similar conflation. But this could hardly be further from the truth. Lovejoy is well aware of the need to account for differences between contexts, recognizing that the intellectual historian 'may, and often does, need to exercise his mind in concepts that... are alien to his and his contemporaries' habitual modes of thinking'. ${ }^{50}$ In similarly Skinnerian fashion, he notes that it is obviously 'true that a historical understanding even of the few great writers of an age is impossible without an acquaintance with their general background in the intellectual life and common moral and aesthetic valuations of that age'. ${ }^{51}$ Lovejoy suggests several types of unit-idea: assumptions or 'unconscious mental habits', such as the Enlightenment preference for simple schemes of ideas;

47) Skinner, 'Meaning and Understanding in the History of Ideas', 37.

48) See Jouni-Matti Kuukkanen, 'Towards a Philosophy of the History of Thought', Journal of the Philosophy of History 3 (2009), 25-54, at 34-5.

49) Skinner, 'Meaning and Understanding in the History of Ideas', 36 , emphasis added.

50) Arthur O. Lovejoy, 'Present Standpoints and Past History', in The Philosophy of History in Our Time, ed. H. Meyerhoff (Garden City, NY: Doubleday Anchor Books, 1959), 179; see also Reflections on Human Nature (Baltimore: John Hopkins University Press, 1961), especially $67-9$.

51) Lovejoy, The Great Chain of Being, 20; 'The Historiography of Ideas'; 'Reflections on the History of Ideas' in The History of Ideas, ed. Kelley, 11-2. 
'Dialectical motives', which are particular turns of reasoning such as the both philosophical and commonplace nominalist motive of reducing the general to its particulars; 'Metaphysical pathos', which is the tendency to arouse a congenial feeling in the audience, as when a thinker obscures or enters into the esoteric; and a specific proposition or principle and its corollaries. ${ }^{52}$ While these are not unit-ideas in my elemental sense, recognition of them is evidently inconsistent with a mere 'fetishism of words' ${ }^{53}$ On the contrary, focusing on them should help us to understand the authentic use of a word or phrase by uncovering the conceptual contexts in which they arose, the mental tics that fuelled them, and the emotional charge they held.$^{54}$ Moreover, Lovejoy exhibits an acute sensitivity to differences of usage within the same context. ${ }^{55}$ For example, he distinguishes between various meanings of Christianity and Romanticism. ${ }^{56}$ He even goes so far as to list thirteen meanings of pragmatism and some sixty-six uses of 'nature' in antiquity. ${ }^{57}$ Indeed, 'Lovejovian' is sometimes used as shorthand for the very attention to detail that Skinner claims Lovejoy disregards. ${ }^{58}$

So much, then, for the claim that Lovejoy merely studies occurrences of words. ${ }^{59}$ But is this criticism more applicable to my conception of elemental unit-ideas? On first glance the case here looks better. One of my previous examples, 'Man', has several uses even in our society; it can denote, for example, either 'male human being' or 'humankind'. Furthermore, I have

52) Lovejoy, The Great Chain of Being, 7-15.

53) Skinner, 'Meaning and Understanding in the History of Ideas', 39.

54) Kvastad, 105-6; Richard Macksey, 'The History of Ideas at 80', MLN 117 (2002): 1083-97, at 1089-90.

55) See Lovejoy, The Great Chain of Being, 4-5.

56) Lovejoy, The Great Chain of Being, 6; 'On the Discrimination of Romanticisms', in Essays in the History of Ideas.

57) Arthur O. Lovejoy, 'The Thirteen Pragmatisms', in The Thirteen Pragmatisms and Other Essays (Baltimore: John Hopkins Press, 1963); 'Appendix' to Arthur O. Lovejoy and George Boas, Primitivism and Related Ideas in Antiquity (Baltimore: John Hopkins Press, 1935), 44756. For a similar point in relation to Skinner's (misplaced) criticism see Francis Oakley, Omnipotence, Covenant, and Order: An Excursion in the History of Ideas from Abelard to Leibniz (Ithaca, NY: Cornell University Press, 1984), 33.

58) For instance, in his review of David Spadafora's The Idea of Progress, David Rothstein remarks that it is 'definitely the book to consult for an extremely thorough, Lovejovian survey of professed beliefs'; see Modern Philology 90 (1993): 544-48, at 544.

59) For further evidence against this claim see John Patrick Diggins, 'Arthur O. Lovejoy and the Challenge of Intellectual History', Journal of the History of Ideas 67 (2006): 181-208. 
pressed for a repositioning of the way in which Lovejoy's particular studies, some of which I have just invoked in his defense, coincide with the Lovejovian methodology. But there is nothing about this methodology which suggests that it would have any difficulty in discriminating between terms and ideas. We just have to carefully distinguish between the different ideas referred to by the same word. In the 'Man' case we describe 'male human being' and 'humankind' as each being a unit-idea (subject, of course, to the possibility that these are in fact idea-complexes which can be further broken down). This is foreshadowed by Lovejoy when he observes that 'since the word is one and the ideas it may express are prodigiously numerous and various, it is, for the historian, often a task of difficulty and delicacy to determine what, in a given writing, the idea behind the word is' ${ }^{60}$ In sum, Skinner's criticism of the history of ideas can only be successful where that history construes the relationship between words and ideas in simplistic fashion. It is simply not applicable to either Lovejoy's historical studies or the Lovejovian methodology, as they hold a more sophisticated understanding of the word-idea relationship.

We may also note that, in his works on the history of political thought, Skinner adopts a methodology - the tracing of the development of ideacomplexes through the history of their elements - that is (his earlier objections notwithstanding) ${ }^{61}$ firmly Lovejovian. ${ }^{62}$ For example, one of the three aims of Skinner's major work The Foundations of Modern Political Thought is to 'indicate something of the process by which the modern concept of

\footnotetext{
60) Arthur O. Lovejoy, 'Author's Preface' to Essays in the History of Ideas.

61) The tension is noted by Bevir, 104 and explicitly denied by Skinner in his Visions of Politics (Cambridge: Cambridge University Press, 2002), I: 178. For discussion, and further doubts about the basis of Skinner's early methodology, see Anthony Burns, 'Conceptual History and the Philosophy of the Later Wittgenstein: A Critique of Quentin Skinner's Contextualist Method', Journal of the Philosophy of History 5 (2011): 54-83.

62) For the related claim that Skinner himself uses the 'influence model' he so denigrates in early methodological papers, see David Boucher, 'New Histories of Political Thought for Old', Political Studies 31 (1984): 112-21, at 118-9; Francis Oakley, “"Anxieties of Influence”: Skinner, Figgis, Conciliarism and Early Modern Constitutionalism', Past and Present 151 (1996): 6o-110, at 64. For the claim that another well-known contextualist work, J.G.A. Pocock's The Machiavellian Moment (Princeton: Princeton University Press, 1975), has a Lovejovian character, see Diggins, $185^{-6}$. Skinner's early methodology seems to be largely accepted by Pocock; see the latter's Political Thought and History: Essays on Theory and Method (Cambridge: Cambridge University Press, 2009), 128-9.
} 
the state came to be formed.... I begin in the late thirteenth century, and carry the story down to the end of the sixteenth, because it was during this period, I shall seek to show, that the main elements of a recognizably modern concept of the State were gradually acquired'. ${ }^{63}$ This Lovejovian tracing of the 'elements' which make up larger 'concepts' suggests that Skinner's focus on authorial intention, and the great lengths to which he goes to establish what that might be in each case, is compatible with the Lovejovian approach. ${ }^{64}$ Indeed, it is actually required, at least insofar as our interest is with the ideas the author intends to express - that is, with Bevir's 'hermeneutic meaning'. ${ }^{65}$ At the very least, this suggests that the standard view of Lovejoy as the archetypical 'internalist' or 'intellectualist' historian of ideas ${ }^{66}$ should be rethought. ${ }^{67}$ If the main requirement for a historian of ideas to count as a contextualist is to show a certain degree of care in interpreting the meaning of texts (allowing, for instance, for the value of contemporary texts and wider culture for grasping that meaning), Lovejoy himself may count as one. But if contextualism is defined in a stronger way, such that it, for instance, prohibits attempts to transcend specific solutions to specific problems in specific situations, ${ }^{68}$ it threatens to become both

63) Quentin Skinner, The Foundations of Modern Political Thought (Cambridge: Cambridge University Press, 1978), I: ix. See also Skinner's similar, though much shorter, story about the 'neo-roman understanding of civil liberty', which 'rose to prominence in the course of the English revolution of the mid-seventeenth century' before disappearing under the liberal conception (Liberty before Liberalism (Cambridge: Cambridge University Press, 1998), ix).

64) As Skinner, like Lovejoy, really seems to be concerned with the smaller idea-complexes that make up larger ones, rather than with elemental unit-ideas, the relationship of the elemental unit-ideas approach to Skinner's historical studies is equivalent to its relationship to Lovejoy's historical studies which I described in section II.

65) Bevir, 27. For discussion see A.P. Martinich, 'Four Senses of "Meaning" in the History of Ideas: Quentin Skinner's Theory of Historical Interpretation', Journal of the Philosophy of History 3 (2009): 225-45; Karsten R. Steuber, 'Intentionalism, Intentional Realism, and Empathy', Journal of the Philosophy of History 3 (2009): 290-307.

66) See, for example, Tim Lacy, 'The Lovejovian Roots of Adler's Philosophy of History: Authority, Democracy, Irony, and Paradox in Britannica's Great Books of the Western World', Journal of the History of Ideas 71 (2010), 113-37, at 123.

67) Cf. Donald R. Kelley, 'Intellectual History in a Global Age', Journal of the History of Ideas

66 (2005): $155^{-67}$, at $155^{-6,162 .}$

68) Skinner, 'Meaning and Understanding in the History of Ideas', 50. 
inconsistent with Skinner's historical practice, ${ }^{69}$ and a recipe for work of little present-day interest. ${ }^{70}$ That Skinner's histories of ideas eschew the excesses of his original methodology, and embrace significant elements of the Lovejovian methodology, may speak volumes. ${ }^{71}$

\section{Conclusion}

I have argued that the relationship between Lovejoy's method and his historical practice is not that which has been supposed. But my aim has not been to show that either is seriously flawed. Rather, the status of his practice has to be reconsidered in order for it to fit with a Lovejovian methodology that realizes the analytical potential of identifying the elemental unit-ideas that constitute idea-complexes. This methodology has, I hope, been shown to provide an account of the emergence of new unit-ideas, the disappearance of old ones, and, by means of its doctrine of forces, a causality of changes in idea-complexes. It has also been maintained that the criticism that the Lovejovian approach fails to account for the context specificity of ideas ignores the plethora of evidence that indicates Lovejoy's familiarity with the issue, and relies upon a confused understanding of that approach. Insofar as contextualism is an attractive proposition, the Lovejovian approach described here can accommodate it.

69) David E.G. Boucher, 'On Shklar's and Franklin's Reviews of Skinner, The Foundations of Modern Political Thought', Political Theory 8 (1980): 406-8.

70) Gordon J. Schochet, 'Quentin Skinner's Method', Political Theory 2 (1974): 261-76, at 269-71, 272-3; Joseph V. Femia, 'An Historicist Critique of "Revisionist” Methods for Studying the History of Ideas', in Meaning and Context, ed. Tully; John G. Gunnell, 'Interpretation and the History of Political Theory: Apology and Epistemology', American Political Science Review 76 (1982), 317-27, at 319 .

71) Skinner has more recently revised his methodology in certain regards, the details of which would take us too far from our topic. See especially 'A Reply to my Critics', in Meaning and Context, ed. Tully; and Visions of Politics, I. His criticism of Lovejoy has remained much the same; see Visions of Politics, I: 57-89, 176 . 